\title{
ENTRE NORMAS E FATOS: DESAFIOS E DILEMAS DA ORDEM INTERNACIONAL *
}

SEBASTĨ̃O C. VELASCO E CRUZ

Os primeiros sinais de mudança já se faziam sentir antes desses eventos, mas foram o lançamento da Perestroika, com o seu correlato externo - o novo discurso de Gorbachev sobre a questão - e, logo em seguida, o colapso do Bloco Soviético os principais responsáveis pela profunda transformação que sofreram nos últimos anos as concepções predominantes sobre a segurança internacional.

É natural que tenha sido assim. Marcado por episódio de poderoso simbolismo, o processo de todo imprevisto e sem igual na história que leva àquele resultado subverte as coordenadas do quadro político mundial, quebra os parâmetros estabelecidos e torna subitamente obsoleta boa parte da agenda que vinha concentrando há muito o melhor dos esforços despendidos pelos especialistas da área. Com o fim do conflito entre blocos, o espectro da guerra atômica parecia finalmente afastado. E, com a predominância do consenso em torno de modelos de sociedade (economia de mercado e democracia liberal) e de valores fundamentais (direitos humanos), o mundo parecia estar ingressando em era uma era radiante de paz e prosperidade.

\section{DA DEFESA NACIONAL À SEGURANÇA COLETIVA}

A Guerra do Golfo e a eclosão quase simultânea dos conflitos étnicos na Europa Central, com os espetáculos de violência brutal a que deram lugar, tornaram rapidamente vetustas aquelas idéias. Não que elas tivessem

\footnotetext{
* Texto preparado para a Conferência Conjunta ISA/CEEISA em Budapeste. 28-30/06/03.
} 
se demonstrado inteiramente infundadas - apesar de tudo, a guerra entre as grandes potências continuava sendo uma hipótese inteiramente descartada, e a matriz liberal-democrática continuava em vigor como modelo sem rival. O âmbito de sua validade é que fora redefinido. Mais do que pensar em termos de uma marcha unida em direção àquele estado de coisas sumamente bom, caberia reconhecer a persistência prolongada de diferenciações profundas no campo das relações internacionais. Essa a idéia comunicada pela metáfora dos dois mundos: aquele do bem estar, do consenso liberal e das relações pacíficas (o centro capitalista), e este outro, dilacerado em conflitos crônicos e guerras pouco convencionais (o antigo Terceiro Mundo) ${ }^{1}$.

Não é difícil entender o impacto desse deslocamento no debate sobre o tema da segurança internacional. O mundo que saía da guerra fria não estava a salvo de ameaças. Algumas eram antigas, como aquelas envolvidas na proliferação nuclear. Muitas, porém, assumiam um caráter pouco tradicional. Era esse o caso do recurso à violência organizada nas disputas pelo poder em regiões da periferia, que ganhava um significado novo na medida em que não estava mais sobredeterminado pela lógica do conflito Leste Oeste. Nesse novo contexto, os conflitos tendem a se manifestar sob novas configurações, fragmentando-se e ganhando freqüentemente conotações étnicas e/ou raciais, com seus corolários sombrios: atrocidades sistemáticas contra populações civis, "limpeza étnica", genocídios, movimentação interfronteiras de massas humanas para escapar a esse destino (o problema dos refugiados). E a por em questão muitas das categorias com base nas quais o tema da paz foi secularmente pensado - a distinção entre violência privada e violência pública, guerra civil e guerra interestatal. ${ }^{2}$

Em associação com outros temas, que passavam a ser discutidos também sob esse prisma - o problema do desenvolvimento econômico ${ }^{3} \mathrm{e}$

1 Cf., James Goldgeier e Michael Mcfaul, "A Tale of Two Worlds: Core and Periphery in the Post-Cold War Era", International Organization, No. 46, 1992, pp. 467-92 e Donald M. Snow, Distant Thunder. Patterns of Conflict in the Developing World, New York, M. E. Sharper, 1997. Para uma crítica certeira do ponto de vista que ela expressa, Cf. K. J. Holsti, "The coming chaos? Armed conflict in the world's periphery", in T.V. Paul e John A. Hall, International Order and the Future of World Politics. Cambridge, Cambridge University Press, 1999, pp. 283-310,

2 Cf. dois trabalhos importantes sobre esse ponto: Martin van Creveld, The Transformation of War, New York, The Free Press, 1991, e Mary Kaldor, New \& Old Wars. Organized Violence in a Global Era. Stanford, Stanford University Press, 2001.

3 Cf. Moahmmed Ayoob, "The Security Problematic of the Third World", World Politics, No. 43, 1991, pp. 257-83. 
o da preservação do meio ambiente 4 - a consideração desses conflitos mistos recolocava em outros termos a problemática da segurança internacional. Mudado estava o foco, que não se concentrava mais nas relações entre os Estados, abrindo-se para abarcar um leque de outros temas - as "novas ameaças". Em nível mais profundo, via-se alterada, igualmente, a definição dos "referentes da segurança", i é, os sujeitos cuja proteção devia ser assegurada. Não se tratava mais de garantir a segurança do Estado concebido este como expressão da coletividade politicamente organizada e fiador da integridade física e moral de seus integrantes -, mas de proteger essas coletividades mesmas, e os indivíduos que as compõem, de ameaças provenientes de variegadas fontes, incluso de seus respectivos Estados.

Dois aspectos adicionais dessa mudança de perspectiva merecem destaque. $\mathrm{O}$ primeiro diz respeito à dimensão militar: ela continua presente (para repelir eventuais agressões de Estados delinqüentes e para por fim a violações flagrantes dos direitos humanos em situações de conflito: o tema das intervenções humanitárias), mas perde sua antiga centralidade. O segundo concerne à natureza das relações entre os atores nesse universo. A concepção clássica de segurança é realista: os Estados interagem estrategicamente, constituindo-se, uns para os outros, em fontes potenciais de ameaça. No novo enfoque, embora o conflito interestatal continue sendo levado em conta, naturalmente, a ênfase passa a recair na cooperação necessária à resolução de problemas comuns. No lugar de "defesa nacional", "segurança coletiva" 5.

4 Cf. Jessica Thomas Mathews, "Redefining Security", Foreign Affairs, Vol. 68, 1989, pp. $162-77$.

5 Esses parágrafos aludem de forma muito ligeira a uma história já relativamente longa e sumamente complexa. Para uma primeira aproximação ao tema, Cf. Ken Booth, "Conclusion: Security Within Global Transformation?", in Ken booth (ed.) Statecraft and Security. The Cold War and beyond. Cambridge, Cambridge University Press, 1999, pp. 338-355; Keith Krause, "Critical Theory and Security Studies: The Research Programme of 'Critical Security Studies", in Cooperation and Conflict. Nordic Journla of International Studies, Vol. 33, No. 3, 1998, pp. 298-333. Barry Buzan, "'Change and Insecurity' Reconsidered", in Stuart Croft e Terry Terrif (eds.), Critical Reflections on Security and Change, London, Frank Cass, 2000, pp. 1-17; Edward A. Kolodziej, "Security Studies for the Next Millennium: Quo Vadis?", ibid, pp. 18-38; Patric M. Morgan, "Liberalist and Realist Security Studies at 2000: Two Decades of Progress?", ibid, pp. 39-71; Steve Smith, "The Increasing Insecurity of Security Studies: Conceptualizing Security in the Last Twenty Years", ibid, pp. 72-101. A coletânea organizada por Michael Sheehan, National and International Security, Burlington, Ashgate, 2000 reune algumas das principais intervenções nesse debate. Para uma idéia do impacto do mesmo na América Latina, Cf. Andrew Hurrel, "Seguridad y violencia en América Latina: un análisis conceptual", in Foro Internacional, Vol. XXVIII, No. 1, 1998, pp. 19-36, e na Europa Cf. Kari Laitinen, "Europe's Security: A Critical Reading of Current Security Ideas in Europe", trabalho apresentado na Conferência Anual da International Studies Association (ISA), New Orleans, março de 2002. 
Observável no âmbito dos estudos acadêmicos, bem como no processo de formulação de políticas, esse deslocamento não se operou sem resistências, nem se realizou de forma completa. Embora na defensiva, os "tradicionalistas" continuavam em suas trincheiras disparando argumentos contra a ampliação do conceito de segurança, que acabaria por torná-lo difuso e imprestável. E se a nova abordagem passava a dar o tom em documentos de política de inúmeros países 6 , no desenho da estratégia de segurança nacional dos Estados Unidos, os novos temas continuavam claramente subordinados a preocupações e objetivos de natureza tradicional - adequação permanente do aparelho militar para a defesa dos interesses nacionais contra ameaças presentes e futuras de origem externa - o que se traduzia na importância dada à capacidade de travar guerras simultâneas em dois teatros distantes, e na destinação de recursos vultosos para garantir a prontidão dos seus efetivos, renovar os sistemas de armamentos e custear atividades de pesquisa e desenvolvimento de tecnologia bélica ${ }^{7}$. Não obstante, no campo das idéias, a nova visão da segurança parecia vitoriosa.

Com as conseqüências que acarretou, o atentado de 11 de setembro de 2001 desarrumou inteiramente o quadro até aqui apresentado. Estamos no meio do torvelinho - no momento em que escrevo, a invasão da Iraque pelas tropas americanas, sem o suporte da ONU, é fato consumado - e ainda é cedo para antecipar exatamente de que maneira o problema da segurança internacional será recolocado quando as condições de uma nova normalidade forem recriadas. Mas a crise que estamos vivendo fez aflorar com grande força inúmeras tensões até então latentes, e já revelou tendências com base nas quais podemos ensaiar alguns prognósticos. É a esse exercício aventuroso que o restante do presente artigo será dedicado.

6 Para uma apresentação sintética das tendências predominantes na América Latina,, Cf. Juan Pablo Soriano, "Redefinir las Instituciones de Segurid en el Continente Americano". Publicado pelo Programa das Américas do Interhemispheric Resources Center (IRC), 2002, www.

${ }^{7}$ Sobre o debate em torno da política de segurança nacional nos Estados Unidos, Cf. Ashton B, Carter e William J. Perry, Preventive Defense. A New Security Strategy for America, Washington, Brookings Institution Press, 1999; Thomas Donnelly, Donald Kagan e Gary Schmitt, Rebuilding America's Defenses. Strategy, Forces and Resources For a New Century. A Report of The Project for the New American Century, Washington, 2000 e Michael E. O'Hanlon, Defense Policy Choices for the Bush Administration, 200-1-05. Brookings Institution Press, 2001. Para uma visão desse debate na perspectiva de um observador externo, Cf. Martha Bárcena Coqui, "La reconceptualización de la seguirid: el debate contemporáneo", Revista Mexicana de Política Exterior, No. 59, 2000, p. 9-31, Lilia Bermúdez -Torres, "La seguridad nacional de Estados Unidos: reconceptualización y tendencias", ibid, pp. 32-72, e, de um ponto de vista interpetativa mais amplo, Gilbert Achcar, "The Strategic Triad: The United States, Russia and China", New Left Review, 228, 1998, pp. 91-126. 


\section{“UM CRIME CONTRA A HUMANIDADE!"}

Em meio à consternação provocada pela violência terrível daquele ato insólito, junto às manifestações de simpatia e de solidariedade que partiam de todos os cantos do mundo, nos dias imediatamente seguintes, podia-se ouvir também, repetidamente, esta exclamação: "um crime contra a humanidade!" Expressão de assombro e indignação, comumente, frase de efeito, às vezes, quando proferida por alguns essa fórmula adquiria sentido preciso e ganhava dimensão programática. Incluem-se nesse terceiro caso os pronunciamentos dos intelectuais identificados com o programa da democracia cosmopolita e da cidadania global.

Tome-se, a título de exemplo, o artigo "Aprender de la Lecciones de Pasado", publicado pelo diário espanhol El País, em 8 de outubro de 2001, com assinatura de David Held e Mary Kaldor ${ }^{8}$. Ali, esse ponto de vista é apresentado de forma expressa:

Os ataques contra as Torres Gemeas do World Trade Center e o Pentágono foram um crime contra a humanidade(...) não foi só um ataque contra as 6.000 pessoas que morreram, foi um ataque contra valores que amamos: a liberdade, a democracia, o sistema de direito e, acima de tudo, a humanidade. É necessário fazer toda a classe de esforços, incluída a ação militar, para eliminar a rede e desacreditar totalmente seu atrativo. Mas esses esforços não devem ser equiparados a uma guerra na acepção antiga. Se não conseguirmos compreender isto, arriscamo-nos a um ciclo interminável de violência e de terror.

Essa afirmativa era suscitada pelo discurso, pronunciado poucos dias antes por George W. Bush, no qual o presidente dos Estados Unidos definia o atentado como um "ato de guerra", lançava um ultimato ao regime do Taliban, e fazia saber ao mundo que ele estava ingressando em uma guerra, fadada a ser dura, suja, e prolongada: a "guerra contra o terrorismo".

Os intelectuais ingleses, em seu artigo, discordavam vivamente dessa definição, que parecia ignorar as experiências acumuladas no enfrentamento das "crises humanitárias" da década e fazia tabula rasa de todos os ensinamentos das novas abordagens sobre segurança internacional.

8 www.noucicle.org/arxiu/lecciones.html 
Na política de segurança do Ocidente há uma perigosa disjuntiva ente o pensamento dominante (...), que está baseado na "velhas guerras", e a realidade no terreno. (...) A linguagem do presidente Bush, com sua ênfase na defesa dos Estados Unidos e na divisão do mundo entre "os que estão conosco e os que estão contra nós", tende a reproduzir a ilusão, extraída da experiência da II Guerra Mundial, de que esta é uma guerra entre estados "bons", dirigidos pelos Estados Unidos, e estados "maus", que acolhem terroristas."

Contra essa postura equivocada, que - ao desconhecer a natureza genuína da ameaça a ser enfrentada - tende a potencializar os fatores geradores do medo e do ódio, Held e Kaldor propõem uma estratégia destinada a galvanizar "corações e mentes", "um movimento a favor da justiça e da legitimidade globais, não dos Estados Unidos". E indicam quais seriam as suas metas básicas:

1. Um compromisso com o sistema de direito, não com a guerra. Os civis de todos os credos e nacionalidades devem ser protegidos(...) Os terroristas devem ser tratados como criminosos e não como adversários militares. Isto não impede uma ação militar sancionada em escala internacional(...) Mas uma ação desse tipo deve ser entendida como uma forma mais enérgica de levar a cabo tarefas policiais(...)

2. Deve-se empreender um esforço massivo para criar uma nova forma de legitimidade política global(...) Isto implicaria a retomada de esforços de paz no Oriente Médio, conversações entre Israel e Palestina, condenação de todas as violações de direitos humanos na região(...)

3. Um reconhecimento a priori de que as questões éticas e de justiça colocadas pela polarização global da riqueza, a renda e o poder(...) não é algo que possa ser deixada nas mãos do mercado.

Convém reler com atenção esse pequeno artigo, pois, embora subscrito por duas personalidades com perfil muito próprio, a posição que ele expressa é partilhada por amplas parcelas da opinião pública na Inglaterra e em outras partes do globo. Como já foi indicado, ele contém em germe todo um programa, mas para efeitos da presente análise o elemento fundamental é a idéia de que o terrorismo deve ser tratado como um crime - no sentido jurídico, e não moral, do termo - com as conseqüên- 
cias diretas que decorrem desse fato: a ação desencadeada para combatê-lo é de natureza policial; os terroristas não podem ser tratados como "soldados" - que têm reconhecido o dever de combater e deixam de ser hostilizados quando depõem as armas - mas como "delinqüentes", que não se livrarão das malhas da justiça enquanto não tiverem purgado a culpa pelos crimes perpetrados.

Justiça; internacional. Pois embora o ataque tenha sido desferido contra alvos norte-americanos, em território dos Estados Unidos, ele foi cometido por rede terrorista transnacional e a injúria produzida por ele atinge em seu conjunto a humanidade. Assim, embora não se negue ao país diretamente atingido o direito de julgar os responsáveis por tais atrocidades, eles devem ser perseguidos através da ação concertada dos governos de todo o mundo e, uma vez aprisionados, devem ser julgados por um tribunal penal especialmente criado para esse fim no âmbito das Nações Unidas. Já no dia seguinte ao atentado de 11 de setembro, era esse o ponto de vista defendido por Martin Shaw, outro intelectual inglês com intensa atividade de publicista e autor de importantes trabalhos no campo das relações internacionais.

The slaughter of thousands of innocent civilians in New York, Washington and Pennsylvania is a truly atrocious crime... President George W. Bush says that 'The US will hunt down and punish those responsible.' Truly, the only answer to such wanton lawlessness is international justice. But this means the enforcement of law, through the identification, arrest and trial of all those found to have been responsible for these crimes against humanity. ${ }^{9}$

Não foi esse o caminho adotado. Duas semanas depois de expressa tal opinião, o presidente Bush declarava guerra sem trégua ao terrorismo; logo a seguir tinha início o bombardeio ao Afeganistão, realizados pela Força Aérea dos Estados Unidos, mas com amplo respaldo da "comunidade internacional". Esses fatos, porém, não bastaram para silenciar os defensores do combate ao terrorismo pela via do direito internacional. Assim - para ficar em terreno já palmilhado - tanto Held quanto Kaldor

\footnotetext{
${ }^{9}$ Martin Shaw, Stop the round of slaughter www.theglobalsite.ac.uk Global Times 12 september 2001.

10 Cf. David Held, "Violence, Law and Justice in a Global Age", e Mary Kaldor, "Beyond Militarism, Arms Races and Arms Control', ambos encontráveis no site do Social Science Research Council, www.ssrc.org/set11/essays.
} 
voltariam a tratar do assunto nos meses seguintes, desenvolvendo e fundamentando, em artigos independentes, suas teses. ${ }^{10}$ Que são reafirmadas, em tom mais incisivo, por Daniele Archibugi, outro dos expoentes do cosmopolitismo democrático.

All those such as bin Laden and his accomplices who have sullied themselves with crimes against humanity ought to be judged by international tribunals before relatives of the victims(...) today the United Nations ought to set up a special Tribunal with judges from both the countries that are victims of terrorism and from Islamic countries and try them, if necessary, in their absence(...) This is the opposite direction from Bush's strategy."11

Seria um equívoco desconsiderar esse ponto de vista sob a alegação de que ele expressa pouco mais que a impotência de seus defensores - os quais, por isso mesmo, poderiam se entregar a devaneios estéreis. Uma dose mínima de sentido histórico basta para nos convencer de que a força ou fraqueza de uma dada posição política varia de acordo com as circunstâncias, e que uma opinião hoje descartável pode voltar à cena pouco depois com vigor inesperado - esse é o caso, aliás, do movimento pela paz nos dias que correm. Proceder daquela maneira seria julgar um argumento por critérios que lhe são externos. Ao invés disso, cabe examinar com atenção o mesmo, para avaliá-lo no mérito.

O problema com a tese de se combater o terrorismo com as armas da lei não reside na força ou fraqueza de seus proponentes, mas na visão pouco realista que eles tendem a esposar do direito internacional. Não é preciso tomar partido no debate a respeito do conceito de direito e sobre se ele se aplica ou não ao direito internacional - devido à ausência nesse domínio de um corpo legislativo, de instâncias dotadas de poder coercitivo, e de sanções organizadas de maneira centralizada - para reconhecer que as características mais salientes deste cria para os defensores da tese em consideração inúmeras dificuldades. Em sua constituição interna, o direito internacional afigura-se como um conjunto horizontal de "regras primárias de obrigação", desacompanhadas de "regras secundárias de mudança e de decisão", bem como de "uma regra de reconhecimento, a qual, ao especificar as "fontes" do direito e ao fornecer

11 Daniele Archibugi, "Terrorism and Cosmpopolitanism", www.ssrc.org/sept11/essays/ archibugi.htm. 
os critérios gerais que permitam identificar suas regras, assegure a sua unidade."12 Estas características se refletem nos princípios de composição da norma e comunicam a esta uma ambigüidade essencial. Esse fato é apresentado de forma lapidar por Agnés Lejbowicz, em seu comentário sobre os procedimentos de escrita das resoluções das Nações Unidas e sobre o seu significado.

A apresentação em artigos, que permite passar de uma idéia à outra sem explicitar a ligação e a razão da passagem (...) permite introduzir uma multiplicidade de pontos de vista e juntar proposições contraditórias. $\mathrm{O}$ enunciado em artigos e alíneas cria espaços vazios, brancos, opera saltos entre as proposições, e torna possível o jogo das interpretações plurívocas. Esses textos de convenção não só negligenciam os princípios lógicos da contradição e do terceiro excluído como funcionam com a contradição e o terceiro excluído para manter as diversas posições políticas umas ao lado das outras, sem que se combatam. (...) Não é também exagero dizer que esses textos têm mesmo o poder de ativar simultaneamente essas moções, sem que uma chegue a subtrair-se à outra ou a suprimi-la: é necessário que juntas, no plano formal, concorram, a despeito do seu conteúdo contraditório, para a formação de um objetivo intermediário, de um arranjo por concessões mútuas. $\mathrm{O}$ sentido desses textos consiste em suscitar a convergência ${ }^{13}$.

Com base em artigo de um especialista, podemos ilustrar essa afirmativa com uma breve referência à discussão jurídica em torno da legalidade da guerra contra o Afeganistão $\mathrm{O}$ debate envolve duas questões interligadas : como caracterizar o atentado de 11 de setembro? A operação contra o regime dos Taliban tem, ou não tem, cobertura legal?

Comecemos com a primeira delas. Trata-se de um crime, sobre isso não paira dúvida - e é amplamente aceito, também, que a expressão "um ato de guerra" tem valor meramente retórico. O problema é que essas duas qualificações não esgotam o campo das possibilidades. Além de crime, passível de sanção judicial, aquele ato constituiu uma "ameaça à

12 H.L.A. Hart, Le concept de Droit. (traduzido do inglês por Michel van de Kerchove). Bruxelas, Facultés Univeersitaires Aint-Louis, 1976, p. 254.

13 Agnés Lejbowics, Philosophie du Drot International. L'impossible capture de l'humanité, Paris, Presses Universitaires de France, 1999, p. 64. 
paz" e um "ataque armado". Essas três categorias não são mutuamente exclusivas, observa o autor, e este entendimento, que se apóia em ampla jurisprudência, está implicado nas Resoluções 1368 e 1373, do Conselho de Segurança da ONU, que reconheceram aos Estados Unidos o direito de autodefesa nos termos do Artigo 51 da Carta ${ }^{14}$

Grenwood menciona a opinião de alguns comentadores, segundo os quais o Conselho de Segurança teria autorizado o uso da força contra o Afeganistão. Mas apenas para refutá-la. “A Resolução 1373 do Conselho de Segurança requeria de todos os Estados que tomassem certas ações econômicas e políticas, mas não dava autoridade aos Estados Unidos para usar a força militar"15 Ao defenderem a legalidade de sua ação, os aliados tinham sólidas razões para fundar o seu caso na alegação do direito de auto-defesa assegurado naquela cláusula.

Esse é o ponto de partida do autor, que conclui sua hábil argumentação afirmando que a ação de guerra esteve em conformidade com o direito internacional. Mas não precisamos seguir o desenrolar de sua análise. A essa altura já colhemos os elementos que nos interessavam: a evidência da complexidade do caso e do caráter contestável das soluções que lhe são dadas. Pudemos observar esses mesmos elementos na controvérsia sobre a legalidade da ação da OTAN na Iugoslávia ${ }^{16}$, e eles se manifestam mais uma vez - e com intensidade incomparável agora - na crise internacional que culmina na invasão do Iraque ${ }^{17}$.

A complexidade dos casos e a natureza essencialmente contestável das soluções que lhes são dadas não são especificidades do direito internacional. Mas os sistemas nacionais de direito dispõem de mecanismos institucionais para encerrar a controvérsia: embora os juristas possam continuar sustentando interpretações conflitantes, para todos os efeitos práticos a pendência deixa de existir quando, esgotadas todas as instâncias de apelação, o supre-

14 Christopher Grenwood, "International Law and the "War against Terrorism", International Affairs, Vol. 78, No. 2, p. 308 (pp. 301-318).

15 Id. Ibid, p. 309.

16 Para uma rápida apreciação dos termos dessa polêmica, Cf, Bruno Simma, "NATO, the UN and the Use of force: Legal Aspects" e Antonio Cassese, "Ex inuiria ius oritur: Are We Moving Toawards International Legitimation of Forcible Humanitarian Contermeasures in the World Community?", ambos publicados no European Journal of International Law, Vol. 10, No. 1, www.ejil.org/journal/Vol10/No1/ab 1.html, Danilo Zolo, "Diritto internazionale e 'guerra umanitaria'", www.odradek.it/giano/201/37/zolo.html e, do mesmo autor, Cosi si distruge il cuore del diritto, www.

17 No imenso material disponível, Cf. Mark Littman, "A Supreme International Crime", The Guardian, 10/03/03, www. Guardian Special Report, "The Legal Case for War with Iraq", The Guardian, 12/03/03, www. 
mo tribunal pronuncia o seu veredicto. Esse dispositivo inexiste no campo das relações internacionais, e os seus pálidos sucedâneos - a Corte Internacional de Justiça e o recém criado Tribunal Penal Internacional - carecem de maior efetividade. As pendências se resolvem através de tratados, onde o poder relativo das cada partes envolvidas é um fator determinante, ou pela criação de situações de fato, as quais o direito internacional deve encontrar fórmulas para acomodar.

Essa observação nos remete à debilidade teórica-política básica na posição que estamos criticando. É que, ao defenderem a "ação de polícia" e o tratamento judicial dos casos de terrorismo internacional e de violações graves dos direitos humanos - onde quer que elas ocorram -, esses autores pressupõem, implícita ou explicitamente, a existência de uma comunidade internacional coesa, movida por esses mesmos valores e dotada dos recursos de poder necessários para agir da forma indicada. Ora, a existência de tal ente é mais do que duvidosa. O que o suceder das crises no pós-Guerra Fria revela é a junção da capacidade e da disposição de intervir em um Estado, que se move estrategicamente na arena internacional segundo o que define como o seu interesse nacional: os Estados Unidos. Em outras palavras, no lugar de "comunidade internacional", o que prevalece no mundo unipolar que se desenha com o fim da Guerra fria é uma estrutura de poder, no âmbito da qual as relações - mesmo as que vinculam os Estados do centro capitalista - são marcadas por crescentes assimetrias ${ }^{18}$.

A despeito da retórica da globalização, mesmo nos primeiros momentos do pós Guerra Fria, não era preciso muito esforço para reconhecer esse fato. Mas foram as tensões provocadas pela crise humanitária da Bósnia e a ação da OTAN na Iugoslávia que forçaram os "cosmopolistas-democráticos " a incorporá-lo em suas análises ${ }^{19}$. O que assistimos no presente, com as manifestações

18 Esse é um dos aspectos centrais da crítica ao programa da "democracia cosmopolita", que formulei no ensaio Democracia e Ordem Internacional. Reflexões A Partir da Perspectiva de Um Grande País Semi-Periférico. IFCH/UNICAMP, "Primeira Versão", 2002 (versão eletrônica desse texto pode ser encontrada no página da International Studies Associations, no portal). A mesma restrição constitui o núcleo da análise desenvolvida por Peter Gowan em seu artigo "Neoliberal Cosmpolitanism", publicado na New Left Review, No. 11, 2001, pp. 79-94.

19 A comparação entre o artigo de Habermas, "Bestialität und Humanität", de 1999, e o seu texto sobre a Paz Perpétua, escrito alguns anos antes, expressa de forma exemplar esse deslocamento. No artigo mais recente, Habermas contrapõe a visão européia, que defende uma idéia universalista dos direitos humanos, à perspectiva dominante nos Estados Unidos, que tende a fazer um uso estratégico da causa dos direitos humanos, ao identificá-la com o interesse nacional americano. Habermas voltaria ao tema posteriormente, como no importante artigo “A Constitution for Europe?", publicado na New Left Review, No. 11, 2001, pp. 5-26, e insistiria nele em sua entrevista ao Nation sobre a guerra ao Iraque. Cf. Danny Postel, "Letter to America: An Interview with Jürgen Habermas", Nation, 16-12-02. 
intensas de inconformidade desse setor da opinião pública com a condução da política externa dos Estados Unidos na crise do Iraque, é como que ao despertar amargo de um sonho pela violência do choque com a realidade.

\section{OS SENHORES DA GUERRA}

Ao observador atento não terá escapado essa ironia. Durante a campanha presidencial George W. Bush atacou sistematicamente seu oponente por sua disposição de mobilizar o poder dos Estados Unidos para solucionar situações de crise que não punham em risco os interesses do país. "Não é tarefa do governo americano promover o 'national building", era a fórmula usada. Contra esse vício dos campeões do globalismo Bush defendia uma estratégia baseada na ênfase à defesa interna, na clara identificação dos interesses nacionais em cada circunstância, na redução do comprometimento de recursos materiais e humanos na Europa, na prioridade nova a ser conferida aos assuntos do hemisfério, enfim, na condução de uma política exterior mais "modesta". Dois anos depois, os Estados Unidos se encontram lançados em uma guerra rejeitada pelas Nações Unidas e encarada como ato de suprema arrogância por setores majoritários da opinião pública mundial. E promete não ficar aí: não haverá sossego enquanto Estados tirânicos continuarem oprimindo seus povos e ameaçando a paz mundial. Esta, a premissa maior da anunciada estratégia de segurança nacional, que "será baseada em um internacionalismo peculiarmente americano, que reflete a união de nossos valores e nossos interesses nacionais." Estratégia que tem como objetivo proclamado “ajudar a criar um mundo não apenas mais seguro, mas melhor."20

Entre a prudência pretérita e a desenvoltura de agora, o trauma do 11 de setembro. No dia 20 desse mês houve a declaração de "guerra ao terror" - não apenas aos responsáveis por aquele ato, mas a "todos os grupos terroristas de alcance global", e a "todas as nações que lhes dêem abrigo". Semanas mais tarde, o presidente dos Estados Unidos anunciava aos participantes da Conferência de Varsóvia sobre o Combate ao Terrorismo sua disposição de não esperar até o momento em que os autores de assassinatos em massa conseguissem as armas de destruição necessárias à plena realização de seus desígnios. A mensagem era claramente dirigida ao Iraque,

20 Casa Branca, The National Security Strategy of the Unitede States of America. Setembro de 2002. 
cujos alegados vínculos com a rede de bin Laden continuavam carecendo de comprovação persuasiva. A partir daí a retórica oficial passa a enfatizar, cada vez mais, a questão das "armas de destruição em massa", que se converte em foco privilegiado de atenção no famoso discurso, pronunciado em 29 de janeiro de 2002, sobre o "eixo do mal". Era a primeira expressão oficial da "doutrina Bush", a qual - em seus conceitos de guerra preventiva e de primazia permanente dos Estados Unidos - foi exposta com franqueza desconcertante no discurso em West Point ("America has, and intends to keep, military strengths beyond challenge, thereby making the destabilizing arms races of other eras pointless" 21 ) e sistematizada no documento de política anteriormente citado. A esta altura, a noção dos Estados Unidos como "a nova Roma" começava a ser debatida na imprensa americana, em colunas prestigiosas dos melhores jornais.

Para alguns, embora marcada pelas circunstâncias excepcionais em que veio à luz, a orientação da política externa do governo Bush não introduz nada de profundamente novo na história dos Estados Unidos. Tal é a interpretação de Robert Kagan, autor das passagens transcritas abaixo:

America did not change on September 11. It only became more itself. Nor should there be any mystery about the course America is on, and has been on, not only over the past year or over the past decade, but for the better past of the past six decades, and, one might even say, for the better part of the past four centuries. It is an objective fact that Americans have been expanding their power and influence in ever-widening arcs since even before they founded their own independent nation. (...) The myth of America's "isolationist" tradition is remarkably resilient. But it is a myth. Expansion of territory and influence has been the inescapable reality of American history, and it has not been an unconscious expansion. (...) Americans have always been internationalists, therefore, but their internationalism has always been a by-product of their nationalism. When Americans sought legitimacy for their actions abroad, they sought it not from supranational institutions but from their own principles. (...) As Benjamin Franklin put it, America's "cause is the cause of all mankind". ${ }^{22}$

21 www.whitehouse.gov/new/reliases/2002/06/print/20020601-3.html

22 Robert Kagan, Of Paradise and Power. America and Europe in the New World Order. New York, Alfred A. Knopf, 2003, pp. 87-8. 
Segundo os defensores dessa perspectiva, entre a política de Bush e a de seus predecessores, nenhuma descontinuidade significativa pode ser observada. Vitoriosos na Guerra Fria, os Estados Unidos saíram do episódio como a única superpotência no mundo, capaz de impor os termos da rendição a seus antigos rivais e de remodelar o mapa geopolítico de forma a estender sua influência a um ponto jamais alcançado.

The end of the Cold War was taken by Americans as an opportunity not to retract but to expand their reach, to expand the alliance they lead eastward toward Russia, to strengthen their relations among the increasingly democratic powers of East Asia, to stake our interests in parts of the world, like Central Asia, that most Americans never knew existed before. ${ }^{23}$

Como nega-lo? Esta foi efetivamente a trajetória seguida - na presença de condicionantes objetivos, sim, mas sob impulso de uma vontade coletiva consciente de si mesma e claramente expressa em concepções estratégicas ${ }^{24}$. Contudo, a interpretação em apreço silencia certos aspectos do processo que são relevantes para o entendimento da crise atual e para a exploração de seus desdobramentos prováveis. O que essa versão obscurece é o fato de que o desenho da "doutrina Bush" resulta do esforço persistente de um grupo de intelectuais ultraconservadores, em franca dissidência com a condução da política externa do Governo Clinton. "Liberalinternacionalistas" e "neo-imperiais". Há um fundo comum nas posições desses dois grupos: o suposto de que seria possível e desejável preservar duradouramente o "momento unipolar" que se produziu com o fim da Guerra Fria - contra a opinião dos realistas recalcitrantes, que sempre consideraram essa configuração de poder como transitória e instável. Mas a partir daí as diferenças são notáveis. Os primeiros apostavam na "globalização" e no multilateralismo (sem excluir, entretanto, o emprego comedido de ações unilateriais) a fim de obter o consentimento voluntário requeri-

23 Id., ibid, p. 67.

24 Para eliminar qualquer dúvida a esse respeito, Cf. Zbignew Brezezinski, The Great Chesseboard. American Primacy and Its Geostrategic Imperatives. New York, Basic Books, 1997; Peter Gowan, The Global Gamble. Washington's Faustian Bid for World Dominance. London, Verso Books, 1999; Gilbert Achcar, La Nouvelle Guerre Froide. Le monde après le Kosovo. Paris, Presses Universitaires de France, 1999; Cesar Guimarães, "Envolvimento e ampliação: A política externa dos Estados Unidos", in Samuel Pinheiro Guimarães (ed), Estados Unidos. Visões Brasileiras, Brasília, IPRI, 2000, PP. 9-63. 
do para que o exercício da supremacia se fizesse de forma mais suave e eficaz. Quanto aos segundos, proclamam a superioridade de seus valores e confiam na realidade do poder incontrastável que detêm para conseguir a aquiescência de todos aos seus objetivos.

De acordo com John Ikenberry, a grande estratégia formulada por esse grupo caracteriza-se pela articulação de sete elementos fundamentais:

1) o firme compromisso com a manutenção de um mundo unipolar, no qual os Estados Unidos não tenha competidor ou igual; 2) a dramatização das ameaças globais e do que deve ser feito para que sejam enfrentadas - visão paranóica que se expressa exemplarmente no jogo de palavras do Secretário de Defesa Rumsfeld sobre os "desconhecidos sabidos" e os "não sabidos desconhecidos" ("known unknowns" e "unknown unknowns"), subentendida a idéia auto-contraditória de que o sistema de segurança deve estar preparado para lidar com essa última categoria de circunstâncias; 3) o abandono do conceito de dissuasão, tido como obsoleto nas condições prevalentes no mundo do pós Guerra Fria - a ameaça não vem mais de grandes potências, que podiam ser dissuadidas pela certeza de que, caso atacassem, seriam igualmente destruídas. A ameaça agora é representada pelas redes transnacionais terroristas; contra elas a única resposta eficaz é a ofensiva; 4) o sacrifício conseqüente do princípio da não intervenção e do conceito de soberania: como não dispõem de territórios a defender, esses grupos devem ser caçados onde quer que se abriguem - se os governos em questão fizerem o trabalho, ou colaborarem com ele, ótimo; caso contrário, com o sem permissão, cabe a nós destruí-los; 5) o desprezo manifesto pelas regras internacionais, os tratados e sistemas estáveis de alianças; 6) a afirmação do papel direto e ilimitado dos Estados Unidos no enfrentamento das novas ameaças; 7) a reduzida importância conferida à estabilidade internacional, como princípio norteador de política - a disposição fáustica de remover obstáculos à realização de seus objetivos, mesmo ao preço de romper o equilíbrio tênue em regiões críticas $^{25}$.

Como avaliar a novidade da política informada por essa proposta? Reposicionamento tático ou estratégico? Mudança de forma, ou de conteúdo? 2002, pp. 44-60. 
Não creio que essa seja a melhor maneira de colocar o problema. Lançar ultimatos não é o modo adequado de cultivar amizades, e não se pratica política de poder com luvas de pelica. Como na arte, em política, além de certo limite a distinção entre forma e conteúdo perde todo o sentido.

Por outro lado, não avançamos muito na avaliação de uma política quando nos atemos às declarações de intenção que a acompanham, ou às exposições doutrinárias que a justificam. Ambas são importantes, mas devem ser encaradas como dimensões da própria política, cujas relações com os demais elementos desta não são nunca evidentes ou unívocas. Quando olhado de perto, o discurso de uma dada política se mostra sempre como algo contraditório e lábil, pois refletidos nele estão os conflitos de interesses e pontos de vista que estruturam o campo dessa política. Conflitos que são permanentemente realimentados pela discrepância de opiniões sobre como lidar com problemas novos, criados por elementos não considerados da realidade que se pretende transformar, ou pela execução bem sucedida da própria política.

A política de segurança do Estado hegemônico não foge a este figurino. Podemos com alguma facilidade caracterizar a perspectiva desse ou daquele grupo, e afirmar com segurança: do ponto de vista ideológico, as diferenças entre "liberais internacionalistas" e "neo-imperiais" são expressivas. Mas não podemos inferir daí que a política externa do governo Bush represente uma ruptura com a política do governo Clinton (os neoimperiais encontram oposição, mesmo na cúpula do Executivo, e nunca chegaram a ditar, integralmente e em todo momento, a conduta do governo norte-americano). Para dar esse passo temos que mudar de foco da atenção, observar as iniciativas que marcam essa conduta, as reações que suscitam e a maneira como estas são enfrentadas.

\section{DE VOLTA A HOBBES?}

A julgar pelo encadeamento de ações e reações provocado pela política externa dos Estados Unidos desde janeiro do ano passado, a resposta à indagação formulada no final do item anterior deve ser positiva: ao que tudo indica, estamos diante de uma posição estratégica nova.

Com efeito, em pouco mais de um ano, a conduta do governo Bush provocou uma fratura exposta na aliança montada no final da II Guerra, abalou seriamente a União Européia, produziu curto circuito no sistema de organizações multilaterais, e lançou o país em uma aventura 
militar de futuro incerto, rejeitada pela ONU e repudiada por setores majoritários da opinião pública mundial. Do ponto de vista diplomático, o desastre não poderia ser maior.

Mais significativa, porém, do que a mera seqüência de fatos é a disposição com que eles são encarados. A todos aqueles eventos, a equipe do presidente Bush assiste com estranha impassibilidade, atitude que os ideólogos neoconservadores explicam sem meias palavras: o episódio iraquiano é apenas o início de um processo de remodelagem da região concernida e, em termos mais abrangentes, da política mundial; as realidades do século XXI condenam os esquemas fixos de alianças - "não é a aliança que define a missão, mas a missão que desenha o perfil dos aliados" - e a rigidez de um quadro de regras cristalizadas; no novo ordenamento que se avizinha a ONU poderá encontrar um papel, mas para isso ela terá que adaptar suas estruturas e passar por uma "reforma conceitual" - caso se agarre à tradição, a ONU estará condenada à inutilidade 26 .

Contudo, diante dessas evidências, cabe formular a pergunta que alimenta a dúvida e incita a pensar. É sempre arriscado emitir julgamentos definitivos sobre acontecimentos quando eles se encontram em pleno curso. O que nos garante que as ocorrências presentes se repetirão amanhã? Como saber se o que vemos hoje são manifestações de tendências profundas, e não, meramente, fenômenos conjunturais. E se os democratas ganharem as eleições presidenciais de 2004? Não haverá o abandono dessa política temerária da imposição pela força e o reatamento com a estratégia mais sábia que predominou no passado próximo? A simples observação dos fatos não nos ajuda muito. Se queremos enfrentar essa questão, devemos tomar distância dos dados empíricos, para formular um raciocínio que se apóie em algo além deles, e que os ultrapasse.

Como atalho para chegar a esse objetivo, vou me valer, mais uma vez, da contribuição de John Ikemberry. Desde o final da década de 80, quando escreveu o seu famoso artigo sobre as origens da hegemonia americana no pós guerra27, Ikemberry vem ampliando e aprofundando a tese que expôs de forma acabada em seu livro After Victory. Institutions, Strategic Restraint and the Rebuilding of Order after Major Wars. Invertendo a ordem de exposição do autor, podemos dizer que o problema histórico de

26 Cf. William Safire, "A frente asiática”, O Estado de S. Paulo, 11/03/03, e Alvin Toffler, "Relações mudáveis de poder deixam ONU para trás", O Estado de S. Paulo, 25/03/03.

27 G. John Ikenberry, "Rethinking the Origins of American Hegemony", Political Science Quarterly, 104, 1989, pp. 375-400. 
fundo que ele procura responder é o seguinte: como entender a persistência, no pós Guerra Fria, dos vínculos políticos e econômicos que soldaram o Bloco Ocidental - contrariando o prognóstico realista, de que o mesmo se dissolveria rapidamente, na ausência da ameaça comum representada pela União Soviética - e qual o destino que o futuro lhes reserva?

A resposta de Ikenberry assume a forma de um argumento teórico abrangente, que se apóia em rico estudo comparativo, de caráter histórico. O tema geral do trabalho é o da construção da ordem internacional pelo Estado dominante, depois da vitória obtida em uma "grande guerra". Não caberia expor integralmente neste artigo a cadeia do argumento e as formulações subsidiárias em que ele se desdobra. Basta dizer que ele repousa na distinção entre três opções estratégicas que se abrem para tal Estado em circunstâncias dessa natureza:

1) a montagem de um esquema baseado no equilíbrio do poder, que lhe permite evitar a emergência de uma potência rival no horizonte de tempo relevante; 2) a opção pela ordem hegemônica, na qual os Estados mais fracos tornam-se reféns de seus interesses; 3 ) a criação de uma ordem 'constitucional', que liga esse Estado aos demais através de uma barganha nos termos da qual ele abdica da capacidade de impor sua vontade contra a resistência dos mais fra$\cos$ (os derrotados na guerra e o membros da antiga coalizão vencedora) e recebe em troca a aquiescência desses Estados a normas institucionais e a organizações que promovem seus interesses de longo prazo e o preservam na posição de liderança. Neste último caso, o Estado mais forte assegura sua posição predominante mediante o exercício consciente da auto-contenção (self restraint).

Como na política doméstica, as instituições operam no sentido de reduzir o rendimento do poder, incluindo os mais fracos nos processos decisórios e garantindo que eles não ficarão à mercê dos mais poderoso. Assiste-se, por essa via, no plano internacional a um processo análogo ao da constitucionalização dos vínculos políticos no interior de cada país. Em estágios avançados do mesmo, torna-se inadequado pensar a relação entre os Estados como um sistema estruturado em constelações de interesses. $\mathrm{O}$ elevado nível de integração alcançado leva a pensar, antes disso, em uma protocomunidade política.

Dois fatores básicos afetam a disposição do Estado preponderante a se lançar em uma estratégia de construção institucional e a sua habilidade para conduzi-la com êxito: 
1) o diferencial de poder que ele detém no momento inaugural quanto maior ele for, maior será o incentivo, e 2) a natureza de sua organização política - Estados com estruturas descentralizadas e porosas, como as democracias representativas, contam com enormes vantagens na montagem de ordens desse tipo.

À luz desse esquema teórico, Ikenberry faz um estudo meticuloso de três episódios históricos: a Paz de 1815 e o estabelecimento do Concerto Europeu; a tentativa frustrada da Liga das Nações, e a reorganização do mundo capitalista sob a égide dos Estados Unidos no pós-guerra, com a reconstrução dos países devastados, a montagem de um amplo sistema de segurança coletiva e a institucionalização da economia liberal. Este último realiza todas as virtualidades do modelo estudado ${ }^{28}$.

$\mathrm{O}$ argumento é forte e sugestivo, mas tem uma limitação que o próprio Ikenberry não deixa de assinalar. Ele oferece uma teoria da constituição das ordens internacionais e de sua "reprodução ampliada"; mas pouco nos diz sobre as tensões internas que as habitam, os fatores passíveis de levá-las a crises mais profundas, as condições em que pode se produzir a sua derrocada. Essa a razão porque parece tão deslocada ao leitor a advertência implícita na conclusão do livro contra a hostilidade de setores da elite norte-americana a normas e organizações que restringem o governo dos Estados Unidos no emprego do poder nacional.

Para a inteligência da situação presente, $\mathrm{o}$ argumento provocativo de Robert Kagan ${ }^{29}$ parece mais adequado. As diferenças de perspectiva entre europeus e americanos são antigas, mas no passado o objetivo comum de conter a ameaça comunista não permitia que elas prosperassem. Com o fim da guerra fria, as discrepâncias - em termos de poder e de concepções de mundo - na aliança se aprofundaram: a conjugação delas explica a crise que afeta as relações transatlânticas na atualidade. Os Estados Unidos continuaram a investir pesadamente em seu aparato militar, e os europeus nunca se dispuseram a acompanhá-los. Recusaram-se a isso, saliente-se, por convicção, não como resultado de decisões ad hoc, ou de mero cálculo. A postura dos Estados Unidos e da Europa nessa dobra de século difere porque eles vêem o mundo com outros olhos e definem seus respectivos papeis, neste, de forma oposta. A Europa rejeita a política de

28 Cf. G. John Ikenberry, After Victory. Institutions, Strategic Restraint and the Rebuilding of Order After Major Wars, Princeton, Princeton University Press, 2001.

29 Op. Cit. 
poder, que mais de uma vez levou o continente à beira da ruína, e abraça $\mathrm{o}$ projeto de transcender a política através da intemporalidade das formas legais. Os Estados Unidos, por sua vez - livres dos traumas da guerra, por sua posição insular, e mais consciente dos perigos que povoam o mundo, fora de sua zona pacificada - continuam a se situar no tempo, confiando em sua força para vencer desafios e manter a ordem que todos prezam. Não há inocência em nenhum dos lados: o apelo à letra da lei e ao princípio moral é a arma do fraco; é com ela que a Europa procura projetar o seu poder no campo da política internacional; por isso se sente com razão ofendida em seus interesses quando os Estados Unidos dá provas de apego menor à norma. Suprema ironia: foi o sucesso do casamento que forjou as condições para o divórcio. A Europa encontrou o caminho da paz e da prosperidade porque a presença militar dos Estados Unidos resolveu o dilema da segurança para a região, ao garanti-la contra ameaças externas e ao aplacar as rivalidades que a dilaceraram, outrora; ao fazer isso, no entanto, criou o ambiente que nutre aquela visão de mundo e gera os recursos de poder necessários para sustentá-la. O choque entre europeus e americanos nada tem a ver com a suposta fixidez dos traços culturais: ele se origina de uma diferenciação funcional. A verdade é que os Estados Unidos não precisam aceitar lições da Europa, pois não necessitam de seu concurso. Se acharem necessário, têm meios para agir por conta própria.

O conflito, portanto, é profundo e duradouro. Segundo o autor, não há muito a fazer com ele: aos americanos, Kagan sugere que sejam mais conscientes de sua superioridade e mais compreensivos; o conselho para os europeus é menos exaltante: eles deveriam se lembrar do quanto o mundo - e eles próprios - necessitam de uma América forte, e se adaptar a esta realidade que não lhes reserva glória, mas pode lhes dar outras alegrias.

O problema com a análise e as recomendações de Kagan - um dos defensores da estratégia neoimperial do governo Bush - é que ele superestima a capacidade dos Estados Unidos de agir unilateralmente com êxito e minimiza as resistências que tal ação pode encontrar. São evidências recentes dessa resistência de a articulação entre a França, Alemanha, Rússia e China no Conselho de Segurança, o insucesso das pressões exercidas para obter o voto do Chile e do México no mesmo foro, a rejeição pelo Parlamento turco do acordo permitindo o estacionamento de tropas americanas no país, e próprio desenrolar das operações no Iraque.

Os trabalhos que comentamos desembocam em dois cenários alternativos. No primeiro, vencida a crispação da conjuntura presente, uma correção de rumos na política externa norte-americana propiciaria a 
retomada do multilateralismo, a recomposição dos vínculos rompidos e o exercício da hegemonia em bases mais consensuais ${ }^{30}$. No segundo, a grande estratégia predominante hoje persiste e é bem sucedida, impondose aos estados que poderiam eventualmente desafiá-la e transformando os Estados Unidos em sede de um verdadeiro império mundial. No que me toca, prefiro finalizar este artigo desenhando um cenário distinto.

Ao contrário dos dois primeiros, ele não terá como referência uma configuração hipotética de relações estabilizadas. Será, antes, um cenário de transição.

Acredito que devemos nos fixar nesse aspecto por dois motivos básicos:

1) o mundo não se organiza politicamente como império, e ainda é longo o caminho que poderia levá-lo a isso; 2) ainda que o unilateralismo agressivo da política externa norte-americana reflua em favor de uma estratégia mais inclusiva e mais branda, os efeitos que ele já produziu não são inteiramente reversíveis: ele relembrou a todos a velho adágio de que a concentração excessiva do poder não é um problema porque este é mal usado, mas porque a qualquer momento ele pode vir a sê-lo - quando Waltz invoca os federalistas e a idéia de "freios e contrapesos" para reforçar esse ponto ${ }^{31}$, ele tem toda razão. Se estou certo, o afastamento já ocorrido em relação ao quadro descrito por Ikenberry não é conjuntural: ele tende a se ampliar em futuro previsível.

Ao efetuar esse deslocamento, a política mundial ingressa em um período marcado pelo confronto aberto de duas tendências opostas:

A primeira toma o nível presente de concentração de poder em escala global como base para a produção de níveis ainda mais elevados, tidos estes como indispensáveis à resolução de problemas de interesse coletivo: controle de armas de destruição em massa, desmonte de regimes ditatoriais, combate ao terrorismo. A segun$d a$ encara a concentração de poder atual como problema e opera

30 Essa é a expectativa de um analista tão fino quanto Perry Anderson, que não é suspeito de simpatia com a causa. Cf.

31 Kenneth N. Waltz, "Structural Realismo after the Cold War". International Security, Vol. 25, No. 1, 2000, pp 5-41. 
no sentido de reduzi-la, tendo estrategicamente a multipolaridade como seu horizonte.

Do ponto de vista da segurança internacional, no cenário que se abre com esse embate as "novas ameaças" escalam e velhas ameaças revivem. No passado, a pretensão declarada por uma grande potência de submeter todas a demais ao seu mando foi responsável por conflagrações de grande envergadura; por que haveria de ser diferente no futuro? Seja qual for o resultado da campanha no Iraque, uma questão tem garantida alta prioridade no planejamento estratégico de qualquer país que não se conforme com a idéia de reverter à condição de província: como conter os movimentos do colosso desatado? Qualquer resposta que se dê a tal pergunta incluirá necessariamente a busca de entendimentos em torno de interesses definidos e as artes da diplomacia. Mas para alguns Estados pelo menos, esses instrumentos serão insuficientes: para dizer não será preciso dispor de forte dentadura. Em linguagem menos figurada, a ameaça iminente que a pretensão imperial faz pesar sobre muitos Estados constitui forte incentivo para que busquem em armas não convencionais a garantia de que necessitam.

Risco incrementado de guerra interestatal, pois. Mas explosão quase certa de conflitos armados de outro tipo. Não é difícil entender porquê. A utopia globalista vê no governo mundial a solução definitiva para o problema de paz; e o império global é a forma historicamente plausível de se aproximar dessa condição inatingível. O equívoco consiste em acreditar que a ausência de antagonismos entre Estados equivale a mundo pacífico. Dadas as desigualdades econômicas e sociais, a solidez das identidades nacionais e a memória de conflitos antigos - entre outros fatores que separam os povos da terra - as condições para a conformação de uma comunidade política capaz de dar legitimidade a um Estado global inexistem. A guerra civil planetária é o resultado provável da tentativa de criá-la por meios coativos. Ora, o império é o resultado tendencial de uma dinâmica de poder expansiva. Sua lógica opera no período de transição e gera os mesmos efeitos. Cabe esperar, portanto, que o avanço da tendência imperial seja acompanhado da multiplicação de conflitos violentos e crônicos, da eclosão recorrente de "pequenas guerras", da generalização da prática do terrorismo.

O cenário da transição, porém, não é determinista. Como foi dito antes, ele emerge do choque entre tendências opostas, e nada indica que a tendência à concentração global do poder terminará por se completar. Ao contrário, há fortes razões, normativas e cognitivas, para apostar que o sis- 
tema caminhe no sentido de uma configuração mais equilibrada. Isso poderá acontecer com uma dose de sacrifício humano maior ou menor. A mudança da política externa dos Estados Unidos favoreceria a segunda hipótese. Em tempos tão sombrios, saber que tal é possível é um motivo a mais para não desesperar.

SEBASTIÃO VELASCO E CRUZ é professor de Ciência Política no IFCH/UNICAMP. Sua publicação mais recente em Lua Nova é "O papel do Brasil no sistema internacional" (n.o 53/2001) 


\section{RESUMOS/ABSTRACTS}

\section{ENTRE NORMAS E FATOS: DESAFIOS E DILEMAS DA ORDEM INTERNACIONAL}

SEBASTIÃO C. VELASCO E CRUZ

Examinam-se os limites e o significado da controvérsia entre "realistas" que invocam fatos e "cosmopolitas" que invocam normas, com referência às perspectivas da ordem internacional após 11 de setembro de 2001. Contra a idéia da retomada pelos EUA do multilateralismo, ou do seu oposto, a idéia dos EUA como sede de um verdadeiro império mundial, propõe-se um "cenário de transição", marcado por turbulências inter- e intra-estatais, sem prejuízo da possibilidade real de uma configuração mais equilibrada no futuro.

Palavras-chave: Ordem internacional; multilateralismo; unilateralismo.

\section{BETWEEN NORMS AND FACTS: CHALLENGES AND DILEMMAS OF THE INTERNATIONAL ORDER}

The limits and the mean ing of the controversy between "realists" who invoke facts and "cosmopolitans" who invoke norms, regarding the prospects of the international order after September 11, 2001, are examined. Against the idea of a retrieval by the USA of multilateralism, or its opposite, the idea of the USA as the center of a true worldwide imperial order, a "transition scenario" is proposed, marked by inter- and intra-state disturbances, notwithstanding the real possibility of a more balanced configuration in the future.

Keywords: International order; multilateralism; un ilateralism. 